\title{
AVALIAÇÃO QUÍMICA, FÍSICA E REOLÓGICA DO PÓ DE GRAVIOLA OBTIDO A PARTIR DO PROCESSO DE SECAGEM DE MISTURAS DE GRAVIOLA E LEITE EM SECADOR DE LEITO DE JORRO
}

\author{
G. F. CARLOS ${ }^{1}$, A. K. T. MACHADO ${ }^{1}$, T. M. DELMIRO ${ }^{1}$, I. P. MACHADO ${ }^{1}$ e M. F. D. de \\ MEDEIROS $^{2}$
}

${ }^{1}$ Universidade Federal do Rio Grande do Norte, Departamento de Engenharia Química E-mail para contato: glaucia_fcarlos@yahoo.com

\begin{abstract}
RESUMO - Misturas de polpa de graviola com adição de 30 e $50 \%$ de leite foram secas em secador de leito de jorro com partículas inertes de polietileno de alta densidade nas temperaturas de 70 e $90^{\circ} \mathrm{C}$. A polpa in natura e as misturas foram caracterizadas quanto ao teor de umidade, sólidos solúveis, $\mathrm{pH}$ e acidez total titulável e massa específica sendo avaliado o comportamento reológico das mesmas com determinação da viscosidade aparente e do índice de fluxo do fluido. Realizaram-se análises de umidade, atividade de água, acidez total titulável e solubilidade do produto em pó. O pó foi reconstituído em água e submetido à determinação da massa específica e avaliação do comportamento reológico. A adição do leite interferiu no comportamento reológico das misturas, no entanto, estas continuaram se comportando como fluidos não newtonianos com características pseudoplásticas, apresentando viscosidades aparentes inferiores a da polpa in natura. Os pós obtidos apresentaram elevada solubilidade em água, atividade de água e umidade dentro da faixa que contempla estabilidade microbiológica e condições adequadas para conservação e armazenamento. A mistura reconstituída apresentou características físicas e químicas compatíveis com a mistura original demonstrando o baixo impacto do processo sobre o produto.
\end{abstract}

\section{INTRODUÇÃO}

A secagem de frutas é realizada com o intuito de diminuir o desperdício durante as safras, fazendo com que o consumo seja ampliado para qualquer período e em regiões onde não são cultivadas. Os estudos de diferentes processos de secagem são realizados com o intuito de obter produtos secos, através de métodos mais econômicos e eficientes. (Alvarado, 2001)

O teor de umidade e a atividade de água consistem em parâmetros importantes na conservação de alimentos. A umidade representa o conteúdo total de água presente no alimento enquanto a atividade de água representa o teor de água livre ou disponível para o alimento interagir com o meio promovendo o desenvolvimento microbiano e surgimento de reações químicas e bioquímicas indesejáveis. (Almeida, 2009) 
No presente trabalho, foram analisadas misturas de polpa de graviola com adição de 30 e $50 \%$ de leite foram secas em secador de leito de jorro com partículas inertes de polietileno de alta densidade nas temperaturas de 70 e $90^{\circ} \mathrm{C}$. A polpa in natura e as misturas foram caracterizadas quanto ao teor de umidade, sólidos solúveis, $\mathrm{pH}$ e acidez total titulável e massa específica sendo avaliado o comportamento reológico das mesmas com determinação da viscosidade aparente e do índice de fluxo do fluido. Realizaram-se análises de umidade, atividade de água, acidez total titulável e solubilidade do produto em pó. O pó foi reconstituído em água e submetido à determinação da massa específica e avaliação do comportamento reológico.

\section{METODOLOGIA EXPERIMENTAL}

A polpa de graviola utilizada foi obtida pelo despolpamento manual da fruta in natura. Após o despolpamento as frutas foram processadas em liquidificador doméstico e peneiradas para eliminação de quaisquer resquícios de casca ou caroço. Foram separadas em porções de $250 \mathrm{~g}$ para congelamento em freezer doméstico a $-20^{\circ} \mathrm{C}$. Para o preparo das misturas, foi utilizado o leite bovino integral pasteurizado.

\subsection{Ensaios de Secagem}

O secador de leito de jorro é constituído de uma coluna cilíndrica $(18 \mathrm{~cm}$ de diâmetro e $72 \mathrm{~cm}$ de altura) com base cônica (ângulo incluso $60^{\circ}, 13 \mathrm{~cm}$ de altura e $3 \mathrm{~cm}$ de diâmetro da entrada do ar), construída em aço inoxidável com visores em acrílico. Acoplado a coluna tem-se um ciclone Lapple (10 cm de diâmetro da coluna) para promover a separação entre o pó e o ar. O pó é coletado na parte inferior do ciclone por sacos plásticos de $300 \mathrm{ml}$. Na Figura 1 apresenta-se o esquema do leito de jorro.

Figura 1 - Esquema ilustrativo do leito de jorro

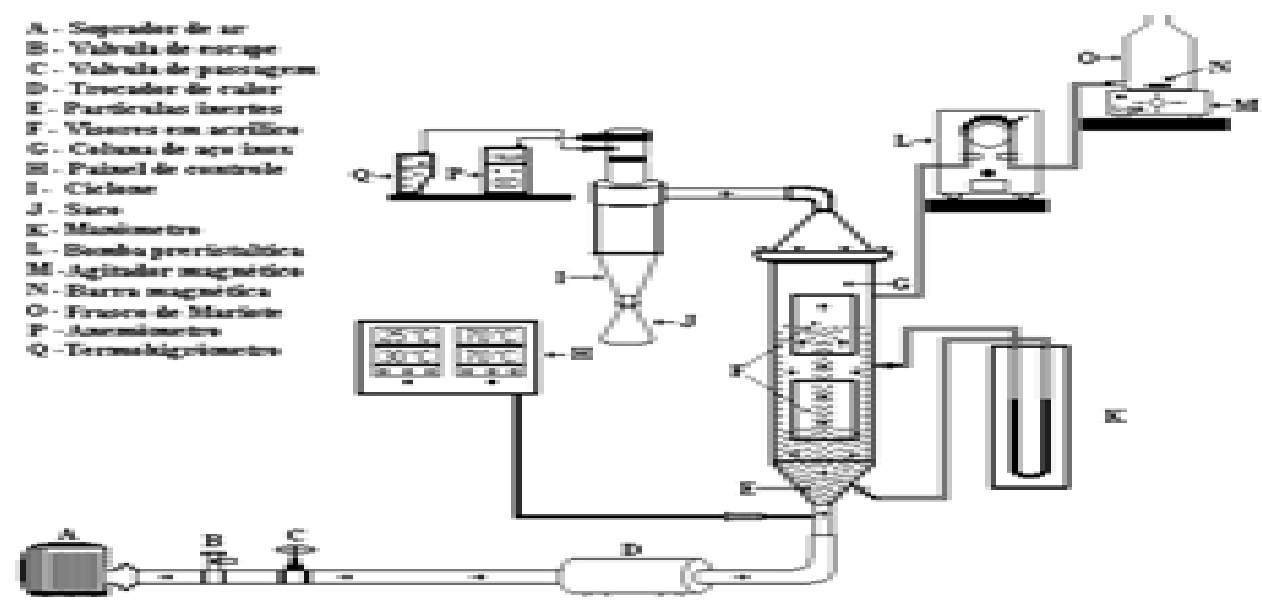

Como material inerte foi utilizado um leito de $2500 \mathrm{~g}$ de partículas de polietileno de alta densidade com diâmetro médio de $0,32 \pm 0,05 \mathrm{~cm}$ e densidade de $0,875 \pm 0,468 \mathrm{~g} \cdot \mathrm{cm}^{-3}$. Em todos os ensaios a alimentação da suspensão foi atomizada com uma vazão fixa de $7 \pm 0,8$ 
$\mathrm{mL} / \mathrm{min}$, sendo realizada de forma intermitente (com 6 minutos de alimentação e 4 minutos de suspensão da alimentação). A velocidade na coluna do ar de secagem foi fixada em $1,3 \mathrm{~m} / \mathrm{s}$. As temperaturas de secagem utilizadas foram de 70 e $90^{\circ} \mathrm{C}$, e as misturas alimentadas com concentração de 30 e $50 \%$ de leite.

\subsection{Análises físico-químicas}

A umidade da polpa in natura e das misturas foi determinada em estufa de circulação de ar a $70^{\circ} \mathrm{C}$ até peso constante e a do pó em balança de umidade com aquecimento por infravermelho. As medidas de atividade de água foram realizados em analisador de atividade de água do tipo AQUALAB e as do $\mathrm{pH}$ em potenciômetros de bancada previamente calibrado. A solubilidade foi determinada a partir da centrifugação do pó reconstituído em água e posterior secagem do sobrenadante em pesa filtros na estufa até peso constante, sendo calculada pela Equação (1).

$$
\text { Solubilidade }=\left(\frac{\left(m_{p f+\text { amostra })}-m_{p f v a z i o}\right) x\left(100+m_{p o ́}\right)}{m_{\text {amostra }} x m_{p o ́}}\right)
$$

A acidez total titulável (ATT) foi determinada por titulação com $\mathrm{NaOH}$, e calculada pela Equação 2).

$$
\operatorname{Acidez}(\%)=\frac{N_{\mathrm{NaOH}} x E q_{\text {ácido }} x V_{\mathrm{NaOH}} x f_{\mathrm{NaOH}}}{m_{\text {amostra }}} \times 100
$$

Onde ${ }^{N a O H}$ é a normalidade da solução de $\mathrm{NaOH}$; $E$ qácido é a equivalente do

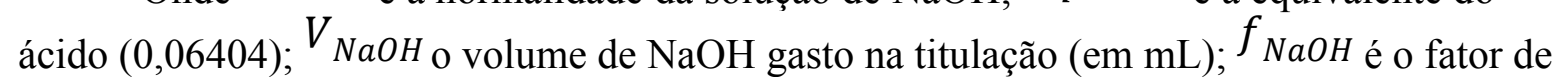

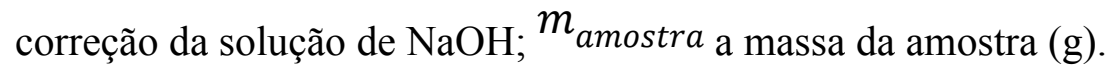

\subsection{Massa específica e ensaios reológicos}

A massa específica da polpa in natura, das misturas e das misturas reconstituídas foi determinada por picnometria líquida utilizando-se picnômetros de $50 \mathrm{~mL}$, previamente tarados e calibrados com água destilada.

Foram obtidas as curvas reológicas da polpa in natura, das misturas e da mistura reconstituída com 50\% de leite em viscosímetro rotatório (Brookfield DV-II+Pro). Realizaram-se medidas do torque e viscosidade aparente em função da velocidade de rotação da haste (Spindle na forma de disco) em amostras de $300 \mathrm{ml}$ do material. Iniciavam-se as medidas na menor velocidade de rotação que era aumentada gradativamente.

\section{RESULTADOS E DISCUSSÕES}

Na tabela 1 são apresentados os resultados das análises físico químicas dos pós. A faixa estabelecida para alimentos secos na forma de pós e estáveis do ponto de vista 
microbiológico é de atividade de água inferior a 0,4 e umidade menor que $5 \%$. Os pós obtidos nos três ensaios encontram-se na faixa recomendada para os dois parâmetros citados anteriormente.

Tabela 1 - Análise das propriedades químicas dos pós obtidos nos ensaios experimentais

\begin{tabular}{cccc}
\cline { 2 - 4 } & $30 \%-70^{\circ} \mathrm{C}$ & $50 \%-70^{\circ} \mathrm{C}$ & $50 \%-90^{\circ} \mathrm{C}$ \\
\hline Umidade (\%) & $7,17 \pm 0,09$ & $5,68 \pm 0,61$ & $4,41 \pm 0,32$ \\
Atividade de água & $0,375 \pm 0,003$ & $0,331 \pm 0,001$ & $0,274 \pm 0,007$ \\
ATT (\%) & $4,46 \pm 0,02$ & $3,22 \pm 0,13$ & $3,81 \pm 0,02$ \\
Solubilidade (\%) & $70,20 \pm 1,38$ & $64,18 \pm 0,19$ & $66,52 \pm 0,21$ \\
\hline
\end{tabular}

Os pós apresentaram solubilidade elevada e compatível com a literatura. Quanto a acidez, observa-se que os pós são muito ácidos, o que era esperado devido à evaporação da água. Na Figura 2 a e b são exibidas as imagens dos pós e das misturas reconstituídas por reidratação destes. Conforme se observa as misturas reconstituídas se apresentam homogêneas e com aspecto bastante semelhante às misturas naturais.

Figura 2 - Imagem do pó e da mistura reconstituída. (a) $\left(30 \%\right.$ de leite, $\left.70^{\circ} \mathrm{C}\right)$ (b) $50 \%$ de leite, $\left.90^{\circ} \mathrm{C}\right)$

(a)

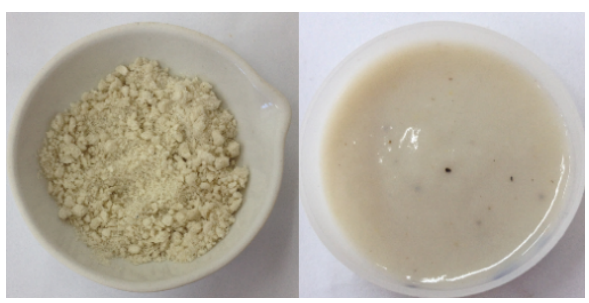

(b)

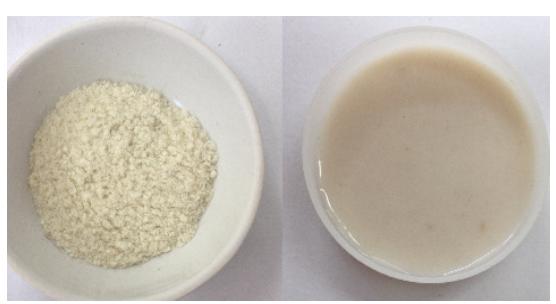

$\mathrm{Na}$ Tabela 1 apresentam-se os resultados da caracterização físico-química e propriedades físicas da polpa in natura, misturas reconstituídas e das misturas não processadas. A adição do leite com menor concentração de sólidos solúveis e maior teor de umidade resulta em misturas mais úmidas e com menor teor de sólidos solúveis do que a polpa de graviola natural. O leite por ser um líquido de caráter básico torna o $\mathrm{pH}$ das misturas mais elevado, comparado ao da polpa in natura, e consequentemente acidez mais baixa. Os pós reconstituíram-se rapidamente em água e apresentaram características físico-químicas próximas as das misturas não processadas, o que demonstra o baixo impacto do processo sobre o produto desidratado. 
Tabela 2 - Características físico-químicas e propriedades físicas da polpa in natura, misturas não processadas e misturas reconstituídas por reidratação do pó

\begin{tabular}{|c|c|c|c|c|c|c|}
\hline & \multirow[t]{2}{*}{ In natura } & \multicolumn{2}{|c|}{ Misturas } & \multicolumn{3}{|c|}{ Reconstituído } \\
\hline & & $30 \%$ & $50 \%$ & $30 \%-70^{\circ} \mathrm{C}$ & $50 \%-70^{\circ} \mathrm{C}$ & $50 \%-90^{\circ} \mathrm{C}$ \\
\hline Umidade (\%) & $82,4 \pm 0,9$ & $85,33 \pm 0,49$ & $85,73 \pm 0,64$ & - & - & - \\
\hline SST ( ${ }^{\circ}$ Brix $)$ & $15,4 \pm 0,9$ & $12,89 \pm 0,07$ & $9,69 \pm 0,16$ & $12,99 \pm 0,07$ & $12,59 \pm 0,33$ & $10,91 \pm 0,16$ \\
\hline $\mathrm{pH}$ & $4,13 \pm 0,02$ & $4,17 \pm 0,08$ & $4,47 \pm 0,02$ & $4,04 \pm 0,06$ & $4,48 \pm 0,02$ & $4,43 \pm 0,11$ \\
\hline ATT (\%) & $0,77 \pm 0,04$ & $0,53 \pm 4,4$ & $0,46 \pm 4,20$ & $0,78 \pm 0,13$ & $0,50 \pm 0,001$ & $0,54 \pm 0,02$ \\
\hline Tempo de & & & & & & \\
\hline $\begin{array}{l}\text { Reconstituição } \\
\text { (s) }\end{array}$ & & - & - & 120 & 80 & 90 \\
\hline$\rho\left(\mathrm{g} / \mathrm{cm}^{3}\right)$ & 1,015 & 1,019 & 1,029 & - & - & 1,048 \\
\hline$\mu(\mathrm{cP})$ a $60 \mathrm{rpm}$ & 963,9 & 395,9 & 264,4 & - & - & 205 \\
\hline $\mathrm{n}$ & 0,483 & 0,359 & 0,374 & - & 0,356 & - \\
\hline
\end{tabular}

$\mathrm{Na}$ Tabela 3 apresentam-se os resultados referentes à acidez total titulável, a solubilidade, a atividade de água e a umidade dos pós obtidos.

Figura 3 - Curvas de viscosidade $(\mathrm{cP})$ versus rotação (rpm)

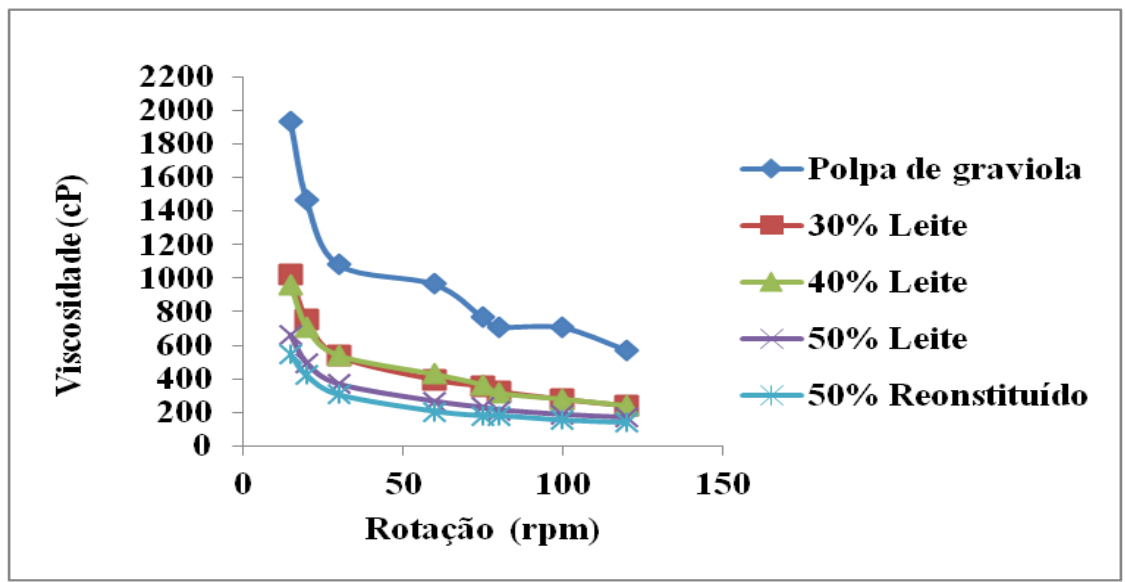

Na Figura 3 apresentam-se as curvas da viscosidade ( $\mu$ ) em função da rotação do viscosímetro. Tanto a polpa de graviola como as misturas nas diferentes concentrações e a reconstituída apresentaram o mesmo comportamento reológico: se comportam como fluidos não Newtonianos $(\mathrm{n}<1)$ e apresentam características pseudoplásticas, já que a viscosidade diminui com o aumento da velocidade de rotação do viscosímetro. A adição do leite interferiu no comportamento reológico das misturas, no entanto, estas continuaram se comportando como fluidos não newtonianos com características pseudoplásticas, porém com viscosidades $(\mu)$ aparentes inferiores a da polpa pura, conforme se observa nos dados apresentados na Tabela 3 para as viscosidades medidas a 60rpm. Ainda na Tabela 3 pode se 
observar que as massas específicas $(\rho)$ das misturas, principalmente da mistura reconstituída, são discretamente mais elevadas do que a da polpa $n$ natura.

\section{CONCLUSÃO}

A polpa de graviola é ácida, com elevado teor de sólidos solúveis, o que se traduz em elevado teor de açúcares. Com adição do leite, as características se modificam e as misturas se apresentam mais úmidas com menor teor de sólidos solúveis e menos ácidas do que a polpa in natura. A adição do leite também interfere de forma importante no comportamento reológico das misturas, que embora continuem se comportando como fluidos não newtonianos com características pseudoplásticas, apresentam viscosidades aparentes inferiores a da polpa. A caracterização dos pós que foram produzidos garante a estabilidade do produto com umidade e atividade de água na faixa indicada para alimentos em pó. Os pós apresentaram curto tempo de reconstituição, solubilidade elevada e compatível com os obtidos por Alsina, 1996. A mistura reconstituída por reidratação do pó apresentou características físico-químicas e reológicas próximas às das misturas não processadas, o que demonstra o baixo impacto do processo sobre o produto desidratado.

\section{REFERÊNCIAS BIBLIOGRÁFICAS}

ALMEIDA, A. R. F. Análise da secagem de pastas em leito de jorro. 2009. 165f. Tese (Doutorado em Engenharia Química) - Departamento de Engenharia Química, Programa de Pós-Graduação em Engenharia Química, Universidade Federal de São Carlos, São Carlos.

ALSINA, O.L.S.; MORAIS, V.L.M.; LIMA, L.M.R.; SOARES, F.H.L. Studies on the performance of the spouted bed dryer for the dehydration of West Indian cherry pulp. In: Drying'96. Mujumdar, A.S. ed.. Hemisphere Publishing Corp., New York, p.867872. 1996.

ALVARADO, J. D.; AGUILERA, J. M. Métodos para medir Propriedades Físicas em Indústrias de Alimentos. Ed. Acribia S.A. Zaragoza, 2001, p.410. 